\title{
Correlation between Serum Digoxin Concentration and Impaired Renal or/and Hepatic Functions in Cardiac Patients
}

\author{
Ahmed Refat Ragabi,2, Maha Khalid Al-Mazroua², Rania Hamed Abdel-Rahman \\ ${ }^{1}$ Department of Forensic Medicine and Clinical Toxicology, Faculty of Medicine, Mansoura University, Mansoura, Egypt \\ ${ }^{2}$ Dammam Regional Poison Control Center, Eastern Region, KSA
}

\begin{abstract}
Digitalis toxicity is characterized by gastrointestinal, neurologic and non-specific cardiac manifestations with striking similarities to the clinical picture of primary congestive heart failure (CHF) making diagnosis of chronic digitalis toxicity in particular relatively difficult. Serum digoxin measurement is today becoming a crucial subject of concern because of the narrow therapeutic window of digoxin besides increasing mortality and morbidity due to its intoxication. The present work is focused on evaluating the clinical value of serum digoxin concentrations (SDCs) in relation to appropriate assessment of chronic digitalis toxicity in cardiac patients. The current study was conducted in the form of a cross-sectional electronic medical record (EMR) review study of patients presently on continuous prescriptions for digoxin with there being zero gaps in therapy for at least 10 days prior to SDC result entered into the Online Analytical Toxicology Request Result (OTARR). There was also a complete clinical examination report as well as a review of the results of serum potassium concentration, liver and kidney functions. This study comprised of 217 adult patients (78 males and 139 females) with mean age \pm SD $(63.18 \pm 19$ years $)$. There were high concentrations of digoxin which led to unstable renal and liver functions. About $12 \%$ of the total cases showed an abnormal serum potassium concentration of electrolyte fluctuations. From this, one can conclude that a regular monitoring of serum digoxin concentration would be seen as mandatory for the verification of digoxin's therapeutic effects and then the subsequent prevention and early diagnosis of chronic toxicity.
\end{abstract}

Keywords serum digoxin concentration, cardiac patients, digitalis toxicity

\section{Introduction}

$\mathrm{D}$ igoxin, a purified cardiac glycoside, is widely prescribed as medications despite there being several adverse drug reactions due to it (Winter, 2009). Although digitalis preparations have been used therapeutically for over two centuries, it is still quite difficult to diagnose digoxin toxicity. The various symptomatic indications with regard to toxicity are still non-specific, in the same way as are electrocardiographic changes. At a specific given Serum Digoxin Concentration (SDC) 'Therapeutic' and 'toxic' concentrations do overlap. For instance, a patient may be able to control ventricular response without any adverse effects, while another may exhibit toxicity. Therapeutic drug monitoring steps up the patient care and is very likely a contributing factor to the suspected decrease in digoxin toxicity; Yet, elevated concentrations are not the only reasons for toxicity (Mordasini et al., 2002; Rathore et al., 2003).

There is a tendency to overlook Digoxin intoxication because of its variable bioavailability and because of differences in its gastrointestinal absorption, distribution and excretion (Gilman et al., 2001). Moreover, it has also shown a narrow therapeutic window which could possibly heighten the risk factors of toxicity in patients being treated with digoxin therapy with a ratio of 5 to $35 \%$ in hospitalized patients (Caspi et al., 1997; Kirilmaz et al., 2012).

It was observed that in cardiac patients, the therapeutic range for digoxin was in the range from 0.9 to $2.2 \mathrm{mg} / \mathrm{ml}$ (Kelly and Smith, 1992). Also, the serum 
digoxin concentrations below and above this range were quite ineffective and toxic as well. There are many arrhythmias along with several other extra cardiac sideeffects, right from headaches, nausea and vomiting up to death (Caspi et al., 1997).

According to a statement made by the American College of Cardiology/American Heart Association (ACC/AHA) Guidelines for Heart Failure in 2009, once the therapeutic range has been reached, it is advisable to go in for SDC measurement. It is also considered proper to bring about a change in toxicity-provoking physiologic parameters, like decreased renal function; after the introduction or discontinuation of an interacting drug; in order to assess clinical response; to assess adherence; or in the presence of clinical signs of digoxin toxicity (Cañas et al., 1999; Jessup et al., 2009).

The present work aims at raising the precautions against digoxin toxicity in renal and hepatic impairment cardiac patients and evaluating the clinical value element of serum digoxin concentrations (SDCs) with regard to appropriate assessment of chronic digitalis toxicity.

\section{Subjects and methods}

\section{Study setting}

This work was conducted as a cross sectional, (Electronic Medical Review) EMR database review study at Damamm Regional Poison Control Center - Eastern Region, KSA.

\section{Inclusion criteria}

Adult patients monitored for SDC in two hospitals (Dammam Medical Complex and Qatif Central Hospital) that were participating in a year-long period from the beginning of April, 2011 until the end of March, 2012.

\section{Exclusion criteria}

Patients aged less than 18 years old, severe heart failure, severe hepatic failure, severe hypertension, a history of acute digitalis toxicity that resulted from intention ingestion of digoxin therapy, patients presently on interrupted prescriptions for digoxin or patient there being zero gaps in therapy for less than 10 days prior to SDC result were excluded from the study.

\section{Study population parameters}

Investigators noted down important and detailed information of all the patients, like their age, and gender as well as their patient code, in-patient or out-patient admission status and medical service type.

Indications for digoxin treatment, clinical manifestations and electrocardiographic changes were consistent with digoxin toxicity and this information was recorded. Digoxin toxicity, if any was diagnosed and also reported.

SDCs assays for adult patients were recorded along with crucial information digoxin dosing data, including dose, route of administration, date of the first and last dose, and the timing of the blood sample relative to the last dose of digoxin $(2,4,6,8$ and 10 hours after dosing).

At present, the status of electrolytes, renal and liver functions values were evaluated at the same time of estimating the SDC. Important laboratory activities and investigations such as blood urea nitrogen, serum creatinine concentration, and both serum ALT and AST levels were also conducted.

\section{Assay procedure}

The received blood samples were centrifuged at 3000 rpm for 5 minutes. Immediate measurement of serum digoxin level was done by immunoassay technology using the Abbott TDx system (Abbott Laboratories, Abbott Park, Ill; assay sensitivity range is $0.3-6.4 \mathrm{nmol} / \mathrm{L}$ [0.2-5.0 ng/mL].

\section{Grouping of the studied patients}

The studied cases were divided into 3 groups according to the obtained serum digoxin level as follows:

- Group A: patients

with therapeutic

serum digoxin level

$0.9-2.2 \mathrm{ng} / \mathrm{mL}$.

- Group B: patients

with subtherapeutic

serum digoxin level

$<0.9 \mathrm{ng} / \mathrm{mL}$.

- Group C: patients

with toxic serum

digoxin level $>2.2$

$\mathrm{ng} / \mathrm{mL}$.

The studied cases were divided into 2 groups according to the stability of hepatic and renal functions as follows (Pincus and Abraham 2006):

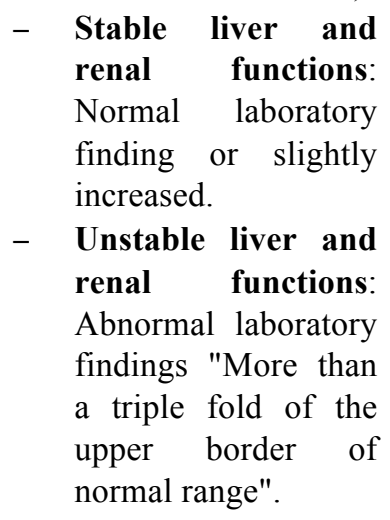

\section{Electronic medical records review process}

Three reviewers conducted the entire review process 'pharmacists'. Taking the help of individual patient records, the individual patient records were access by way of medical record number access into the EMR. Predefined data points fed into a standard type Excel worksheet was set up on a share drive that was password protected which was to be used by every single reviewer 
in order to get the abstraction data information. Then every patient was reviewed on an independent basis to be reviewed for agreement purpose followed by checks carried out by the third reviewer to see if there were still any other discrepancies identified. Data extractors had to have total agreement amongst them. The study was approved by the Medical Ethics Committee of the Dammam Regional Poison Control Center with complete confidentiality of patient information records as maintained by keeping patients names anonymous.

\section{Statistical analysis}

There was a statistical analysis of the entire data with the help of the present SPSS statistical package Version 19. This data was further presented as mean \pm standard Deviation (S.D.). There was also a comparison exercise done between the two groups that was carried out with the help of $t$-test and $p$ value was considered statistically significant if $<0.05$.

\section{Results}

The current work comprised of 217 patients ( 78 males and 139 females with mean age \pm SD: $63.18 \pm 19$ years). Therefore, a total of 217 SDCs were requested in the entire 12-month (1 year) study period.

Tables (1) and (2) show the different characters of the patients. These patients were studied and analyzed against vital benchmarks like age, gender, admission status, manifestations of digoxin toxicity, associated electro-cardiographic changes, liver and renal functions as well as levels of potassium. In this case, about eightyeight patients were excluded for being identified and later confirmed as 'eutherapeutic' and classified as bearing "no toxicity".
There were laboratory experiments done which led to findings detected with regard to the different SDCs. These were presented in Table (3). While patients with digoxin toxicity showed a majorly higher mean SDC, those that did not, were seen to be having subtherapeutic or eutherapeutic SDC (P value $\leq 0.05)$.

It was also observed that there was a drastic decrease in the serum levels of BUN, creatinine, AST and ALT and a much higher and distinct decrease in the serum potassiumlevel when compared with subtherapeutic SDCs group.

One notices in Table (4) the digoxin concentrations and dosing data with regard to the medical indication for digoxin, its dosage, as well as the time of sampling and route of administration.

Figure (1) illustrates the indication of requesting SDC. About $54.8 \%$ of patients were part of routine assessment to check for indications of toxicity. About $39.2 \%$ had suspected toxicity while the rest of the requests had suspected failure of therapy $(3.2 \%)$ and below average compliance (2.8\%).

Figure (2) showed the relationship between different categories of SDC as well as the reason for requesting Digoxin concentration. Almost half the requests - $52 \%$ of the routine requests identified abnormal SDCs $(6 \%$ toxic levels and $46 \%$ subtherapeutic level).

Figure (3) shows the percentages of patients needing dosage adjustment of digoxin and/or interval. About $24 \%$ of the cases needed readjustment of dose or interval.

Table1: Statistical analysis of age, gender, admission status, renal functions status, liver functions status, and serum potassium level in the studied patients $(n=217)$.

\begin{tabular}{|l|c|c|}
\hline Age in years mean (range) & \multicolumn{2}{|c|}{$63.8 \pm 19$} \\
\hline Gender & Male 78 (36\%) & Female 139 (64\%) \\
\hline Admission Status & No & $\%$ \\
Inpatient & 183 & $84.3 \%$ \\
Outpatient & 34 & $15.7 \%$ \\
\hline Renal functions status & 169 & $77.9 \%$ \\
Stable & 48 & $23.1 \%$ \\
Unstable & & \\
Liver functions status & 191 & $88 \%$ \\
Stable & 26 & $12 \%$ \\
Unstable & & \\
Serum potassium level & $88 \%$ \\
Normal Level $(3.5-5.5 \mathrm{mEq})$ & 191 & $10.2 \%$ \\
Hypokalaemia $(<3.5 \mathrm{mEq})$ & 22 & $1.8 \%$ \\
Hyperkalaemia $(>5.5 \mathrm{mEq})$ & 4 & \\
\hline
\end{tabular}


Table 2: Percentages of symptoms and or electrocardiographic changes in patients with abnormal digoxin concentration $(n=129)$.

\begin{tabular}{|c|c|c|}
\hline & \multicolumn{2}{|c|}{ No. (\%) of Patients } \\
\hline & $\begin{array}{l}\text { Subtherapeutic Digoxin Concentration } \\
\qquad(<0.9 \mathrm{ng} / \mathrm{mL}) \\
(\mathrm{n}=103)\end{array}$ & $\begin{array}{c}\text { Toxic Digoxin Concentration } \\
(>2.2 \mathrm{ng} / \mathrm{mL}) \\
(\mathrm{n}=\mathbf{2 6}) \\
\end{array}$ \\
\hline Associated Symptoms \&/or ECG changes & $95(92.2 \%)$ & $25(96.2 \%)$ \\
\hline \multicolumn{3}{|l|}{ Symptoms } \\
\hline Anorexia & $2(1.9 \%)$ & $2(7.6 \%)$ \\
\hline Nausea & $1(1.9 \%)$ & $6(23.1 \%)$ \\
\hline Vomiting & $5(4.9 \%)$ & $5(19.2 \%)$ \\
\hline Abdominal Pain & $17(16.4 \%)$ & $5(19.2 \%)$ \\
\hline Diarrhea & $1(0.97 \%)$ & $4(15.3 \%)$ \\
\hline Dizziness & $7(6.7 \%)$ & $2(7.6 \%)$ \\
\hline Headache & $4(3.8 \%)$ & $1(3.8 \%)$ \\
\hline Confusion & $16(15.5 \%)$ & $0(0 \%)$ \\
\hline Visual Changes & $1(0.97 \%)$ & $1(3.8 \%)$ \\
\hline Palpitation & $6(5.8 \%)$ & $7(26.9 \%)$ \\
\hline Cough & $1(0.97 \%)$ & $1(3.8 \%)$ \\
\hline Dyspnoea & $10(9.7 \%)$ & $4(15.3 \%)$ \\
\hline \multicolumn{3}{|l|}{ Electrocardiographic Changes } \\
\hline Atrial Fibrillation & $13(12.6 \%)$ & $7(26.9 \%)$ \\
\hline Bradycardia ( 50 beats/min) & $5(4.9 \%)$ & $2(7.6 \%)$ \\
\hline Junctional Tachycardia & $0(0.0 \%)$ & $0(0 \%)$ \\
\hline Sustained ventricular tachycardia & $1(0.97 \%)$ & $0(0 \%)$ \\
\hline Sinus arrest & $4(3.8 \%)$ & $1(3.8 \%)$ \\
\hline Heart block & $0(0 \%)$ & $4(15.3 \%)$ \\
\hline
\end{tabular}

Table 3: Statistical analysis correlating serum digoxin concentration (SDC), blood urea nitrogen, serum creatinine, serum potassium, ALT, and AST between studied groups (n= 217).

\begin{tabular}{|c|c|c|c|}
\hline 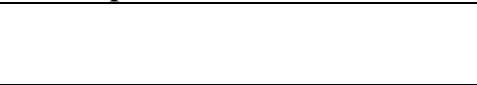 & $\begin{array}{c}\text { Therapeutic SDC Group (n } \\
=\mathbf{8 8})\end{array}$ & $\begin{array}{c}\text { Subtherapeutic SDC Group } \\
(n=103)\end{array}$ & $\begin{array}{c}\text { Toxic SDC Group } \\
(n=26)\end{array}$ \\
\hline \multirow{2}{*}{$\begin{array}{l}\text { SDL }(\mathrm{ng} / \mathrm{mL}) \\
\text { Mean } \pm \mathrm{SD}\end{array}$} & $1.19 \pm 0.26$ & $0.67 \pm 0.17$ & $2.75 \pm 1.2 *$ \\
\hline & \multicolumn{3}{|c|}{ All Groups $(1.02 \pm 0.8)$} \\
\hline $\begin{array}{l}\text { Blood urea nitrogen }(\mathrm{mg} / \mathrm{dl}) \\
\text { Mean } \pm \text { SD }\end{array}$ & $62.6 \pm 36.2$ & $57.77 \pm 41.3$ & $171.5 \pm 91.3^{*}$ \\
\hline $\begin{array}{l}\text { Serum creatinine }(\mathrm{mg} / \mathrm{dl}) \\
\text { Mean } \pm \mathrm{SD}\end{array}$ & $1.58 \pm 1.16$ & $1.61 \pm 1.51$ & $1.97 \pm 1.86$ \\
\hline $\begin{array}{l}\text { Serum potassium }(\mathrm{mEq} / \mathrm{L}) \\
\text { Mean } \pm \mathrm{SD}\end{array}$ & $4.2 \pm 1.05$ & $5.3 \pm 1.3$ & $3.9 \pm 1.1 * *$ \\
\hline $\begin{array}{l}\text { Serum ALT }(\mathrm{IU} / \mathrm{L}) \\
\text { Mean } \pm \mathrm{SD}\end{array}$ & $57.8 \pm 19.2$ & $52.81 \pm 49.8$ & $93.7 \pm 32.5^{*}$ \\
\hline $\begin{array}{l}\text { Serum AST }(\mathrm{IU} / \mathrm{L}) \\
\text { Mean } \pm \mathrm{SD}\end{array}$ & $62.08 \pm 25.9$ & $42.9 \pm 23.7$ & $130.2 \pm 45.9 *$ \\
\hline
\end{tabular}

* $P<0.05 ; * * P \leq 0.01$ 
Table 4: Digoxin dosing data in the studied patients $(n=217)$.

\begin{tabular}{|c|c|}
\hline Indication for digoxin & n (\%) \\
\hline Heart failure & $51(23.5 \%)$ \\
\hline Both atrial fibrillation and heart failure & $151(69.6 \%)$ \\
\hline $\begin{array}{l}\text { Others e.g. myocardial infarction, ventricular septal defect complication, other types of cardiac } \\
\text { arrhythmia }\end{array}$ & $15(6.9 \%)$ \\
\hline \multicolumn{2}{|l|}{ Digoxin Dosage (mg/day) Mean (range): 0.17 ( $0.01-0.625)$} \\
\hline \multicolumn{2}{|l|}{ Time of Sample } \\
\hline At 2 hours & $3(1.4 \%)$ \\
\hline At 4 hours & $6(2.8 \%)$ \\
\hline At 6 hours & $200(92.1 \%)$ \\
\hline At 8 hours & $6(2.8 \%)$ \\
\hline At 10 hours & $2(0.9 \%)$ \\
\hline \multicolumn{2}{|l|}{ Route of administration } \\
\hline Oral & $194(89.4 \%)$ \\
\hline IV & $23(10.6 \%)$ \\
\hline
\end{tabular}

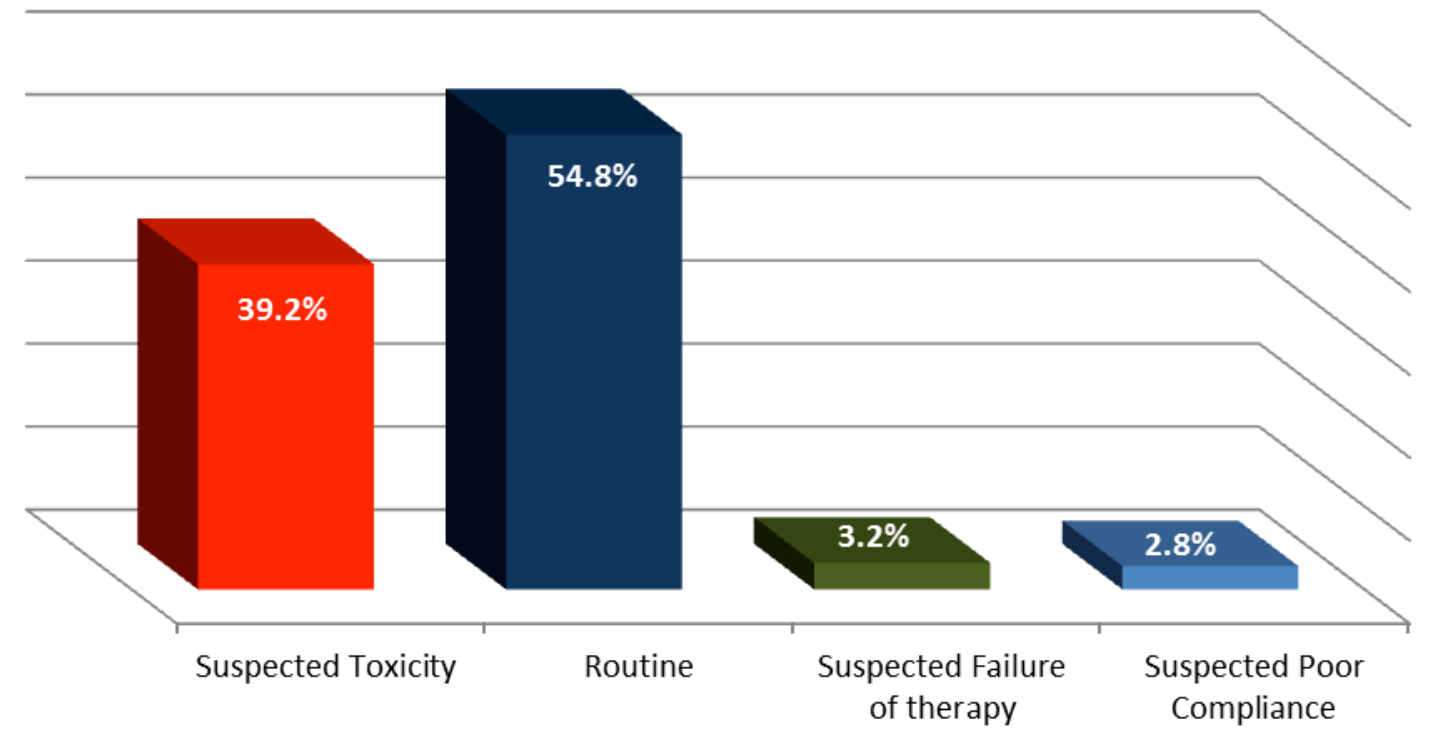

Figure 1: The indication of requesting serum digoxin concentration "SDC" $(\mathrm{n}=\mathbf{2 1 7})$. 


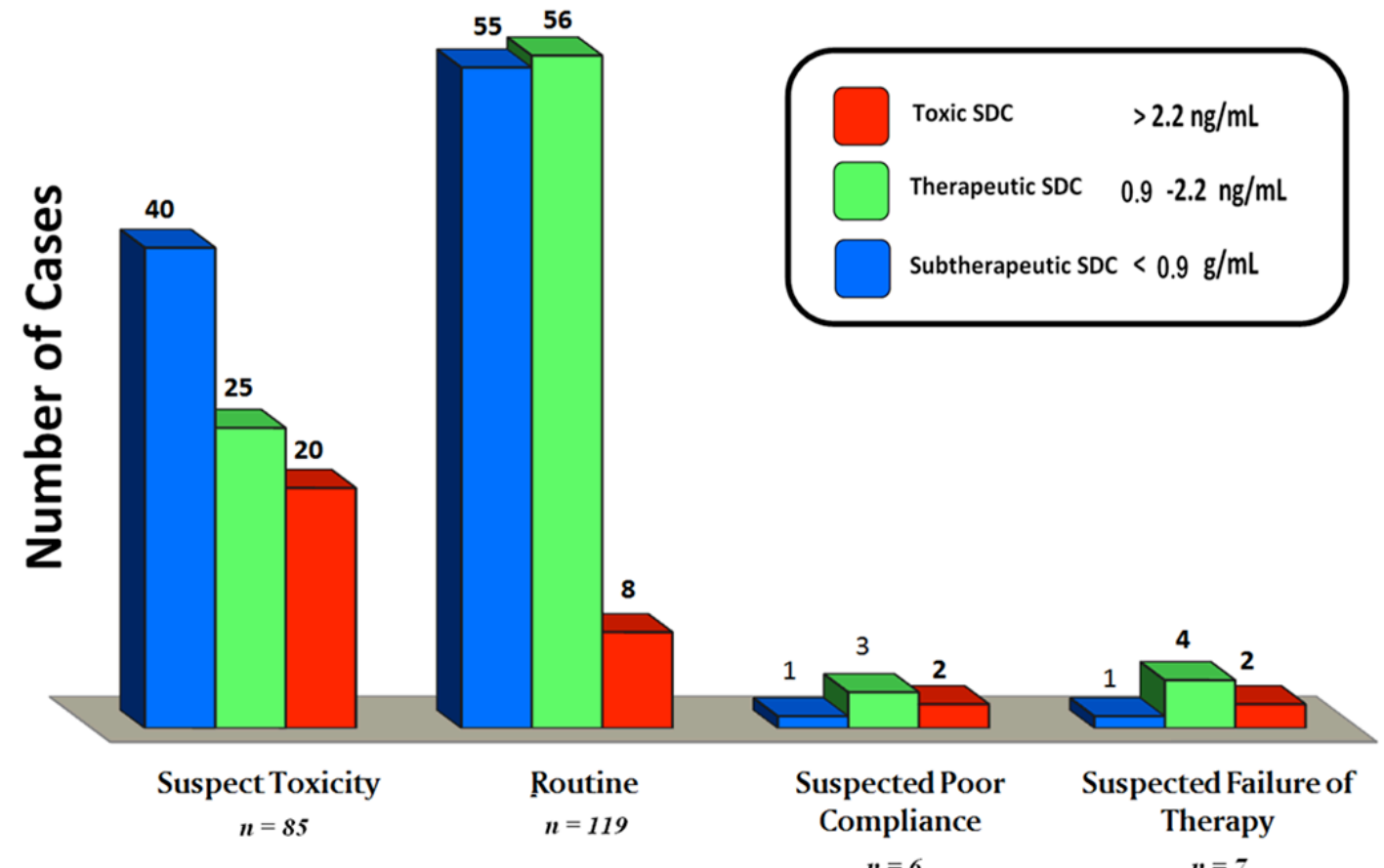

Figure 2: Relationship between different categories serum digoxin concentration (SDC) and the reason for requesting it $(n=217)$.

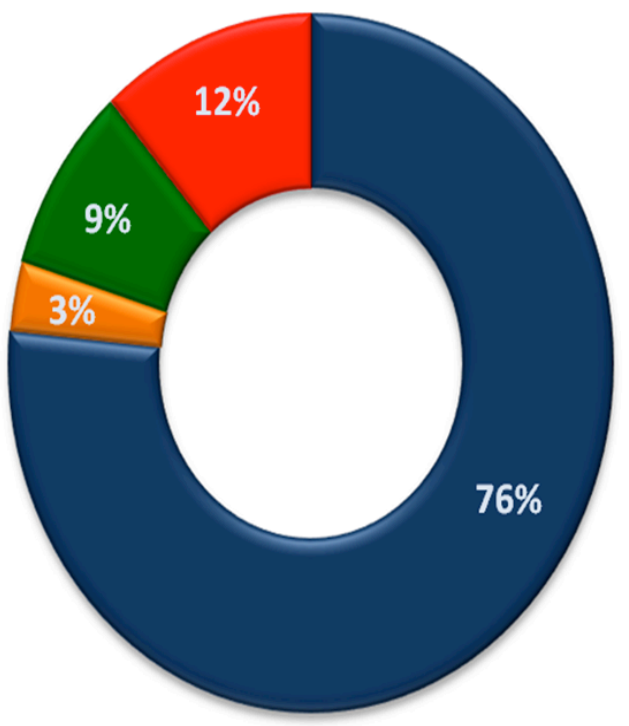

No change in Digoxin Dosage or Interval $(n=166)$

(hange in Digoxin Dosage by Increase $(n=26)$

Change in Digoxin Dosage by Decrease ( $n=20)$

Change in digoxin interval by increase or decrease $(n=4)$

Figure 3: Doughnut Chart of percentages of patients requiring readjustment of digoxin dosage and/or interval (total $n=217)$.

\section{Discussion}

This study presently being conducted consisted of 217 patients $(36 \%$ males and $64 \%$ having mean age \pm SD: $63.18 \pm 19$ years). About 129 patients (59.4\%) exhibited at least one sign, symptom, or an electrocardiographic change that hinted at digoxin toxicity $(20.2 \%)$ or subtherapeutic digoxin concentration $(79.8 \%)$. It was seen that the most common symptom associated with digoxin toxicity was high palpitation. Moreover, toxic digoxin concentration was connected to non-statistically major and many more episodes of palpitation, nausea, vomiting and abdominal pain. At the same time, more or less the same results were observed in another study by Zibzeenezhad and Gharchehm (2007). It was also seen that the patients admitted to emergency departments 
because of digoxin intoxication complained of various problems. This included problems ranging from mild gastrointestinal complaint to syncope caused by severe bradycardia. What is of essence is that none of these complaints are specific to digoxin intoxication (Kirilmaz et al., 2012).

According to Kanji and MacLean (2012) digitalis toxicity creates a toxidrome that is accompanied by gastrointestinal, neurologic, electrolyte, and nonspecific cardiac manifestations. Even in today's modern times, chronic toxicity is not easy to identify. This is largely because of its non-specific manifestations. Naturally, serum glycoside concentrations are extremely vital for effective diagnosis in this kind of population. Also, Koda-Kimble et al. (2005) believed that it was proper predictors of an elevated SDC that helped in understanding clinical signs and symptoms of digoxin toxicity were only fair predictors of an elevated SDC ( $>$ $2 \mathrm{mg} / \mathrm{ml}$ ).

In current circumstances, there were many electrocardiographic occurrences and alterations that happened to a great extent in cardiac patients who had toxic digoxin concentration than in cases with subtherapeutic concentration. Therefore, one had to depend on Atrial fibrillation and heart block to identify the most frequent finding in toxic cases. It became the norm to check the patient for any arrhythmia occurring in a patient who has received digoxin. Premature ventricular beats and atrial fibrillation were the mostly encountered ECG changes found in the study conducted by (Kirilmaz et al., 2012).

That digoxin reversibly halts the sodiumpotassium pump and thus inhibits sodium from being pumped out of cells and potassium from being pumped in. Moreover, potassium competes with digoxin in terms of respect to binding to the $\mathrm{Na}, \mathrm{K}$ pump. Therefore, as the serum potassium concentration is reduced for example by diuretics, the inhibition of the $\mathrm{Na}, \mathrm{K}$ pump by digoxin is further facilitated (Katzung and Parmley, 2004). In consequence, the depletion of intracellular potassium might occur, and is connected digoxin-induced arrhythmia (Wang et al., 2010).

All studied cases called for SDCs. About 88 patients were found to be eutherapeutic without any manifestations of toxicity. Those having digoxin toxicity $(11.9 \%)$ with a higher mean SDC $(2.75 \pm 1.2)$ than those with sub-therapeutic $(0.67 \pm 0.17)$ or eutherapeutic SDC $(1.19 \pm 0.26)$.

The current work presently has a lot of overall incidence of digoxin toxicity and was at $11.9 \%$, higher than that found previously by Mahdyoon et al. (1990). After having conducted a detailed sample of 994 heart failure patients, it was seen that $56 \%$ had digoxin; diagnosis of digoxin intoxication was seen to have affected just $5 \%$ of cases. Also, Garg et al. (1997) observed the incidence of hospitalization for presumed digoxin toxicity was about $0.9 \%$ in the placebo group with and only $2 \%$ in the digoxin group.

The 3 groups indicated similar factors such as age and gender. The mean SDCs were also situated within the normal range in different age groups. As against this, Miura et al. (2000) studied the connection between SDC values and the incidences of digoxin toxicity in 899 Japanese cardiac patients receiving digoxin. Advancing age was also seen to be one of the predisposing factor for digoxin toxicity, which the authors suggested that the SDC therapeutic range for patients aged 70 years or older should be redefined as $0.5-1.4 \mathrm{ng} / \mathrm{mL}$.

According to Goldbergerand Goldberger (2012), toxicity has risks that are likely to occur with serum concentrations $>2 \mathrm{ng} / \mathrm{ml}$ and is almost certain at $>3$ $\mathrm{ng} / \mathrm{ml}$. As per another analysis, it was also seen that SDCs $>1.2 \mathrm{ng} / \mathrm{ml}$ could possibly be harmful (Adams et al., 2005). The serum digoxin concentration for chronic heart failure is recommended at not more than 0.6-1.2 $\mathrm{ng} / \mathrm{ml}$ (Kockova et al., 2011).

Several large clinical study initiatives demand a redefinition of the generally-accepted safe, and therapeutic range for digoxin therapy of $0.9 \mathrm{ng}$ per $\mathrm{mL}$ to $2.2 \mathrm{ng} / \mathrm{mL}$ (Winter, 2009). As seen in another report, this once accepted SDC therapeutic range was challenged by showing the symptom relief for heart failure at SDCs between $0.5 \mathrm{ng} / \mathrm{mL}$ and $0.8 \mathrm{ng} / \mathrm{mL}$ (Rathore et al., 2003). Similarly, the present results clarified that 52 cases (20.1\%) showed SDC ranged between $(0.5-0.9 \mathrm{ng} / \mathrm{mL})$ without any kind of manifestations just for routine follow up.

As part of the present work, it was seen that 48 patients had impaired renal functions whereas 26 cases indicated disturbed liver functions and a sharp decrease in the mean serum levels of AST (130.2 \pm 45.9$)$ and ALT (93.7 \pm 32.5$)$. With regard to the digoxin intoxicated group, one noticed a substantial hike in the serum levels

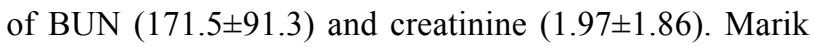
and Fromm (1998) thus observed that the mean creatinine level was about 3 . As for the other side, Kirilmaz et al. (2012) reported relatively lower levels of urea and creatinine levels $(1.5 \pm 0.6)$.

Moreover, hypokalaemia and hyperkalaemia were seen in $10.2 \%$ and $1.8 \%$ of cases respectively. A huge decrease was observed in the serum potassium level in the toxic digoxin group when compared with subtherapeutic SDCs group.

It has been widely accepted that deteriorating renal functions and electrolyte abnormalities (hypokalemia) predispose patients to digoxin toxicity (Goldbergerand Goldberger, 2012). Our study deals with all these factors except creatinine. This element differed majorly $(\mathrm{P}<0.5)$ between the toxic and sub-therapeutic 
groups. Although the serum creatinine levels showed a tendency to be higher in patients with toxic digoxin concentration than those without intoxication, creatinine is not the best predictors of renal function, and creatinine clearance would have likely been more indicative (Piergies et al., 1994).

Serum creatinine and potassium are known to better correlate with digoxin toxicity (Orrico et al., 2011).Binding of digoxin to the $\mathrm{Na} / \mathrm{K}$-ATPase transport system is inhibited by high levels of potassium. Thus, hypokalaemia increase digoxin toxicity, and hyperkalaemia is claimed to be protective (Dawson and Buckley, 2011).

Atrial fibrillation and heart failure were the commonest conditions $(69.6 \%)$ consistent with indications of digoxin therapy in this study whereas sole diagnosis as heart failure was found in $23.5 \%$ of our case series. The mean daily digoxin dosage was 0.17 . In contrast, Kirilmaz et al. (2012) reported that 50.7\% of patients received digoxin for only heart failure. The authors also stated that $23.7 \%$ of patients were on the drug for atrial fibrillation while $25.4 \%$ received digoxin for both conditions. Daily digoxin dose taken by most patients was $0.25 \mathrm{mg}$.

The present study used about $95.8 \%$ of patients' samples that were taken 6 hours or later after the last dose. The concentrations of digoxin concentrations were measured 6 hours or later so as to avoid any wrong assessment caused by the distribution characters of digoxin. Also, samples taken after 6 hours enable more accurate estimation of the body's digoxin burden (Dasgupta, 2008; Dawson and Buckley, 2011). The frequency of digoxin concentrations determined before 6 hours after intake was relatively low in our study $(4.2 \%)$ denoting that a responsible physician is not ignorant of this aspect.

In the case of Digoxin, there is quite a long initial distribution phase of about $4-8$ hours that lasts $4-8$ hours indicating distribution from the central compartment to peripheral tissues compartments. The elevated digoxin plasma concentrations during the distribution phase are mostly clinically irrelevant and might prompt clinicians to unnecessary actions such as adjusting the digoxin dose (Mulder et al., 2010).

Routine indication (54.8\%) was seen to be the most widely-used reason for requesting SDC in the current research while $39.2 \%$ had suspected toxicity. Other requests concerned suspected failure of therapy (3.2\%) and poor compliance (2.8\%). Sidwell et al. (2003) studied the utility of 100 SDCs drawn at Christchurch Hospital in New Zealand and categorized 53\% of requests as routine indication without clear landmark to the accurate and correct therapeutic range.

A majority of SDC results obtained in study $(76 \%)$ did not lead to clinical action, such as dose adjustment, drug holding and or interval changes.A huge percentage of around $24 \%$ of the studied cases required re-adjustment of dose by increase in $12 \%$ or decrease in about $9 \%$ and interval changes $(3 \%)$. These findings were completely different from another study conducted by Orrico et al. (2011) who clarified that the majority of SDCs ordered in their medical group setting for stabilized cardiac patients provided little clinical action with just only one case who needed dose lowering.

The results of this study indicated that the SDCs measured in cardiac patients receiving digoxin therapy is appropriate as it could provide highly useful information which could ameliorate the clinical decision concerning diagnosis of chronic digoxin toxicity. Furthermore, clinical manifestations of digoxin toxicity were not sufficient to be used for evaluation of drug toxicity separately. Hence, it is recommended that periodical monitoring of serum digoxin concentrations should be mandatory in all patients receiving digoxin especially when considering the narrow therapeutic index of this drug.

\section{References}

Adams KF, Patterson JH, Gattis WA et al., (2005): Relationship of Serum Digoxin Concentration to Mortality and Morbidity in Women in the Digitalis Investigation Group Trial. A Retrospective Analysis. J Am Coll Cardiol. 46: 497-504.

Cañas F, Tanasijevic MJ, Ma'luf $\mathrm{N}$ et al., (1999): Evaluating the appropriateness of digoxin level monitoring. Arch Intern Med.; 159 (4):363-368.

Caspi O, Zylber-Katz E, Gostman O et al., (1997): Digoxin intoxication in a patient with end stage renal disease: efficacy of digoxin-specific Fab antibody fragments and peritoneal dialysis. Therap Drug Monitor. 19 (5):510-515.

Chan KE, Lazarus JM, and Hakim RM (2010): Digoxin associates with mortality in ESRD. J Am Soc Nephrol. 21:1550-1559.

Dasgupta A (2008): Digoxin. So Many Interferences and How to Eliminate Them. In: Handbook of Drug Monitoring Methods. Therapeutics and Drugs of Abuse. Humana Press Incorporation, Totowa, NJ. Ch. 6, pp. 111-131.

Dawson A and Buckley N (2011): Digoxin. Medicine. 40:3, 122-124.

Garg R, Gorlin R, Smith T et al., (1997): The effect of digoxin on mortality and morbidity in patients with heart failure. N Engl J Med. 336:525-533.

Gilman GA, Rall TW, and Neis AS (2001): The Pharmacological Basis of Therapeutics. 10th ed. McGraw Hill, New York. 
Goldberger ZD and Goldberger AL (2012): Therapeutic Ranges of Serum Digoxin Concentrations in Patients with Heart Failure. Am J Cardiol. 109:1818-1821.

Jessup M, Abraham WT, Casey DE et al., (2009): Guidelines for the Diagnosis and Management of Heart Failure in Adults: a report of the American College of Cardiology Circulation. 19(14):1977-2016.

Kanji S and MacLean RD (2012): Cardiac glycoside toxicity: More than 200 years and counting. Critical Care Clinics. 28(4):527-535.

Katzung BG and Parmley WW (2004): Drugs used in heart failure. In: Basic \& Clinical Pharmacology, Ninth ed., Katzung BG. McGraw Hill, New York. 201-215

Kelly RA and Smith TW (1992): Recognition and management of digitalis toxicity. Am J Cardiol. 69(18):108G-118G.

Kirilmaz B, Saygi S, Gungor H et al., (2012): Digoxin intoxication: An old enemy in modern era. Journal of Geriatric Cardiology. 9: 237-242.

Kockova R, Skvaril J, Cernohous M et al., (2011): Five year two center retrospective analysis of patients with toxic digoxin serum concentration. Int $\mathrm{J}$ Cardiol. 146 (3):447-448.

Koda-Kimble MA, Young LY, Kradjan WA et al., (2005): Applied Therapeutics: The Clinical Use of Drugs. Lippincott Williams \& Wilkins, Baltimore.

Mahdyoon H, Battilana G, Rosman H et al., (1990): The evolving pattern of digoxin intoxication: observations at a large urban hospital from 1980 to 1988. Am Heart J. 120:1189-1194

Marik PE and Fromm L (1998): A case series of hospitalized patients with elevated digoxin levels. Am J Med. 105:110-115.

Miura T, Kojima R, Sugiura Y et al., (2000): Effect of aging on the incidence of digoxin toxicity. Ann Pharmacother. 34(4):427-32.

Mordasini MR, Krahenbuhl S, and Schlienger RG. (2002): Appropriateness of digoxin level monitoring. Swiss Med. Wkly. 132:506-512.
Mulder VC, Oudemans-Van Straaten HM, Zandstra DF et al., (2010): Massive ingestion of cardiac drugs: toxicokinetic aspects of digoxin and sotalol during hemofiltration. Clin Toxicol. 48(3):218-221.

Orrico KB, Wu M, and Wilson AR (2011): Assessment of the Appropriateness of Serum Digoxin Concentration Measurement in a Medical Group Setting. Journal of Managed Care Pharmacy. 17(9):695-700.

Pincus MR and Abraham NZ (2006): Interpreting laboratory results. In: McPherson RA, Pincus MR, eds. Henry's Clinical Diagnosis and Management by Laboratory Methods. 21st ed. Saunders Elsevier, Philadelphia. Ch. 8.

Piergies AA, Worwag EM, and Atkinson AJ (1994): A concurrent audit of high digoxin plasma levels. Clin Pharmacol Ther. 55:353-358.

Rathore SS, Curtis JP, and Wang Y (2003): Association of serum digoxin concentration and outcomes in patients with heart failure. JAMA. 289(7):871878.

Sidwell AI, Barclay ML, Begg EJ et al., (2003): Digoxin therapeutic drug monitoring: an audit and review. NZ Med J.; 116 (1187):U708.

Wang M-T, Su C-Y, Chan ALF et al., (2010): Risk of digoxin intoxication in heart failure patients exposed to digoxin-diuretic interactions: a population-based study. British Journal of Clinical Pharmacology. 70 (2): 258-267.

Winter ME (2009): Basic Clinical Pharmacokinetics, 5th ed. Lippincott Williams \& Wilkins, Baltimore.

Zibzeenezhad M and Gharchehm M (2007): The applicability of International Reports Toxicity to Iranian Patients. Iranian Cardiovascular Research Journal. Vol. I, No. 1. 


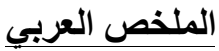

\section{العلاقة بين مستوى الايجوكسين و الاضطرابات في وظائف الكبا والكلى في مرضى القلب \\ أحمد رفعت رجب1،2، مها خالد المزروع² رانيا حامد عبد الرحمن1}

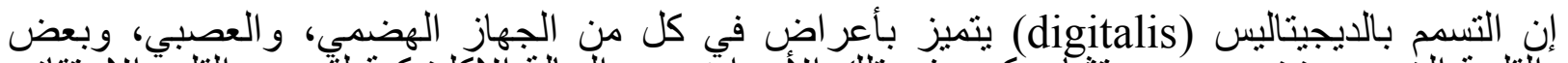

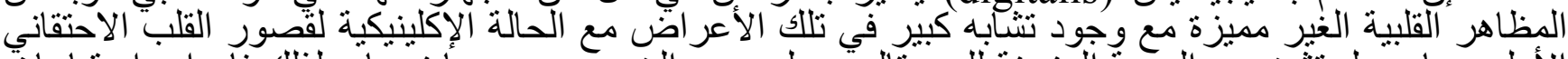

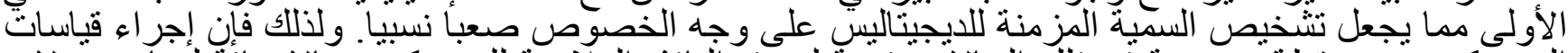

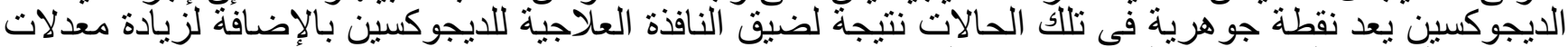

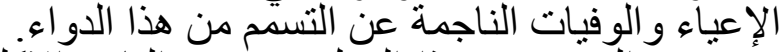

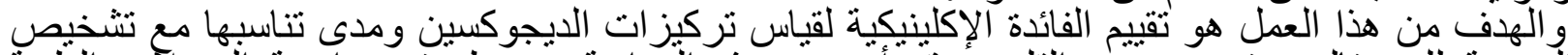

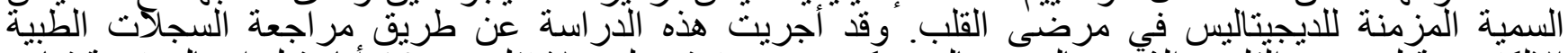

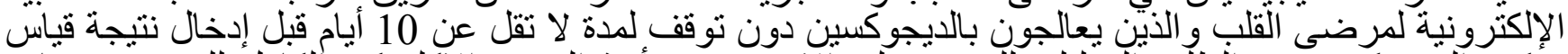

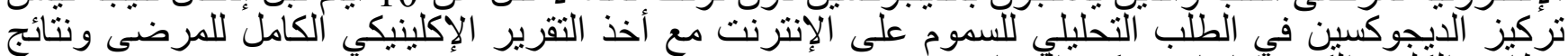

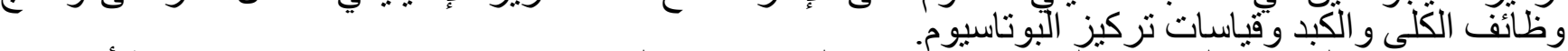

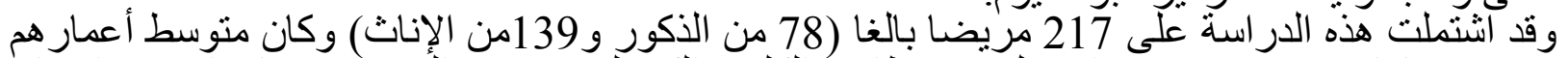

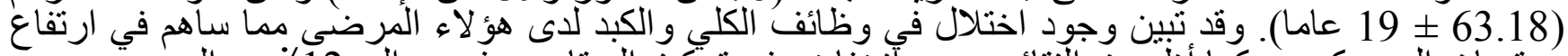

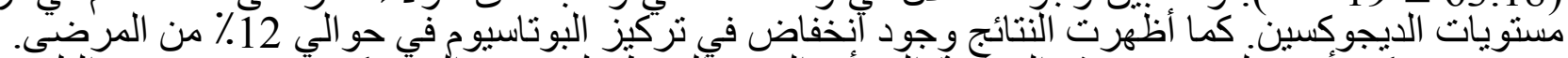

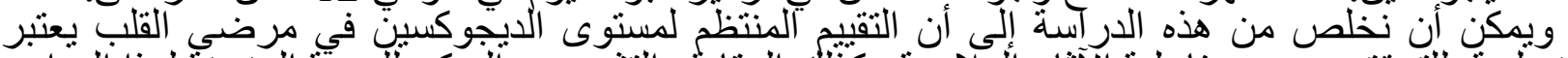

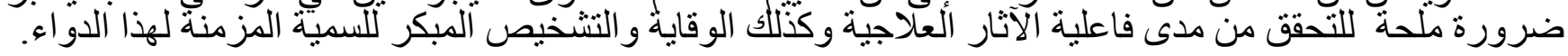

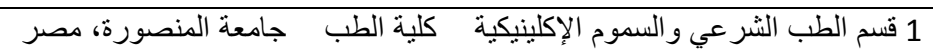

2 المركز الإقليمي لمر اقبة السموم بالدمام. المنطقة الشرقية، الطبة، المملكة العربية السعودية 